\title{
MATERNAL AND PERINATAL OUTCOME IN TWIN PREGNANCIES
}

\author{
Mercy Rodrigo Rexy Rodrigo ${ }^{1}$, Karthika Krishnamurthy²
}

${ }^{1}$ Senior Assistant Professor, Department of Obstetrics and Gynaecology, Thoothukudi Medical College, Thoothukudi. ${ }^{2}$ Assistant Professor, Department of Obstetrics and Gynaecology, Thoothukudi Medical College, Thoothukudi.

\begin{tabular}{l}
\hline ABSTRACT \\
\hline BACKGROUND AND OBJECTIVE \\
Twin pregnancy is a high-risk pregnancy associated with high maternal and perinatal morbidity and mortality. This study is \\
conducted for evaluation of obstetric and perinatal outcome in our hospital.
\end{tabular}

\section{MATERIAL AND METHODS}

This prospective study was conducted in Thoothukudi Medical College Hospital in Department of Obstetrics and Gynaecology between March 2014 to February 2016 over a period of two years in twin pregnancies with gestational age more than 30 weeks and outcomes were studied.

\section{RESULTS}

Incidence of twin pregnancy was 9.64 per 1000 live births. $96 \%$ of cases are booked and had regular antenatal checkups. Among them, $75.82 \%$ of pregnant women belonged to the age group of $20-29$ years and $60.43 \%$ were multiparous and $39.56 \%$ were primiparous women. Even though there was no maternal mortality, pregnancy complications were significantly higher in twin pregnancies. Most common obstetric problems seen in our study are preterm labour (25.27\%), nutritional anaemia (37.36\%), preeclampsia $(17.58 \%)$, and premature rupture of membranes $(13.18 \%)$. The other complication noted were antepartum haemorrhage (4.39\%) postpartum haemorrhage (9.89\%), oligohydramnios (6.59\%), polyhydramnios (2.19\%), hyperemesis gravidarum (6.59\%), gestational diabetes mellitus (1.09\%). Only $13.18 \%$ of patients had no complications. More than one complication was seen in most of the patients. Most common presentation of the foetuses during delivery of twin babies was cephaliccephalic presentation followed by cephalic-breech and breech-cephalic. Caesarean delivery was the most common mode of delivery. Caesarean section rate was $70 \%$ in our study. Incidence of perinatal morbidity requiring admissions in Neonatal Care Unit was $62.08 \%$. Major reasons are prematurity, low birth weight, respiratory distress. Among the twins delivered, 14.28\% were very low birth weight and $64.83 \%$ were low birth weight babies. Only $20.87 \%$ were normal weight babies. Discordant growth in twins was observed only in $4.39 \%$ of cases. The perinatal mortality rate was $10.43 \%$ and the major causes of death are respiratory distress, pulmonary haemorrhage, disseminated intravascular coagulation, sepsis, which are the complications of prematurity.

\section{CONCLUSION}

Prematurity was the major issue in twin pregnancies. So, regular antenatal checkups, nutritious diet, adequate rest, maternal corticosteroids therapy, and short-term tocolytic therapy in cases of preterm labour and institutional delivery with good neonatal care unit set up will definitely improve the outcome in twin pregnancy.

\section{KEYWORDS}

Twin Pregnancy, Chorionicity, Preterm Labour, Low Birth Weight, Maternal Morbidity, Neonatal Morbidity.

HOW TO CITE THIS ARTICLE: Rodrigo MRR, Krishnamurthy K. Maternal and perinatal outcome in twin pregnancies. J. Evolution Med. Dent. Sci. 2016;5(66):4726-4729, DOI: 10.14260/jemds/2016/1077

\begin{abstract}
INTRODUCTION
The term multiple pregnancies refer to a pregnancy in which there are two or more foetuses. The most common multiple pregnancy is twin pregnancy. This may result from a single ovum (monozygotic) or from two ova (dizygotic). Monozygotic twinning is a random event. However, the incidence of dizygotic twins is on the increase. The factors known to be associated with dizygotic twinning are 1) Increased maternal age 2) Artificial reproductive techniques 3) Race 4) Hereditary 5) Nutritional status. $(1,2, \& 3)$ Now, the prevalence varies from 2 to 20 per 1000 live births.
\end{abstract}

Financial or Other, Competing Interest: None.

Submission 02-04-2016, Peer Review 04-08-2016,

Acceptance 10-08-2016, Published 17-08-2016.

Corresponding Author:

Dr. Mercy Rodrigo Rexy Rodrigo,

Senior Assistant Professor,

Thoothukudi Medical College,

Thoothukudi.

E-mail: mercyravi2003@gmail.com

DOI: $10.14260 /$ jemds/2016/1077
All the physiological changes that take place in pregnancy are exaggerated in multiple pregnancies. Due to these exaggerated physiological changes, increased levels of placental hormones and large size of uterus, several maternal and foetal complications occur. The maternal complications in early pregnancy are spontaneous abortion, hyperemesis gravidarum. Due to increased demand for iron and folate in order to meet the increased red cell mass and additional iron requirements of multiple foetuses, iron-deficiency anaemia, or dimorphic anaemia commonly occurs in these patients.

Gestational diabetes is also on the rise due to the effect of diabetogenic hormones of pregnancy especially human placental lactogen. Other complications commonly seen are gestational hypertension or preeclampsia, urinary tract infections due to urinary stasis, preterm labour, antepartum haemorrhage, polyhydramnios, preterm premature rupture of membranes, malpresentations, prolonged labour, prolapse of umbilical cord, increased operative vaginal delivery, and caesarean section. Postpartum complications like postpartum haemorrhage, subinvolution of uterus, sepsis, lactation difficulties are more common in multiple pregnancies. $(4,5, \& 6)$ 
The major foetal complications in twin pregnancy are prematurity, intrauterine growth retardation, and low birth weight. The other complications inherent to twinning are discordant growth of twin, twin-to-twin transfusion syndrome, acardiac twins, death of one foetus in utero, and congenital anomalies. These are more common in monozygotic twins. The incidence of congenital anomalies is considerably greater. Major anomalies are seen in $2 \%$ and minor malformations in $4 \%$ of twins. The major malformations occur in monozygotic twins. Maternal age related chromosomal anomalies are seen in dizygotic twins. Perinatal mortality in twin pregnancy is three to tenfold higher than that in singletons. Prematurity is the leading cause of perinatal mortality in twin pregnancy. All the complications of prematurity namely respiratory distress syndrome, sepsis, pulmonary haemorrhage, and necrotising enterocolitis causes mortality. The morbidity increases if the babies are also discordant.

This study was conducted to assess maternal and neonatal complications and pregnancy outcome of twin pregnancy. The results may be useful for evaluating the quality of the obstetric care and neonatal services and may guide in the management protocols in future.

\section{MATERIALS AND METHODS}

This observational study was conducted in the department of Obstetrics and Gynaecology, Thoothukudi Medical College from March 2014 to February 2016. Total number of cases included was 91 . Women with twin pregnancy completing 30 weeks of gestation irrespective of parity status, age, and medical disorders admitted in our hospital during the study period were included in this study. But, patients discharged after conservative management was excluded.

Thorough obstetric history and family history were taken. Careful physical examination was done to note the associated complications like anaemia, hypertension. Per abdomen examination was done to find the lie presenting part, liquor status, and foetal heart rate. Pelvic examination was done to note the presenting part, membrane status, and adequacy of pelvis. All necessary investigations were done. USG was performed to identify the chorionicity and congenital anomalies. Placenta was examined to confirm chorionicity. Details about the gestational age at the time of delivery, delivery interval between twins, birth weight were recorded. Both mothers and babies were followed till discharge. Twins admitted in neonatal care unit were also followed till discharge and finally findings were compiled and analysed.

\section{RESULTS}

Total number of deliveries from $1^{\text {st }}$ March to $29^{\text {th }}$ February was 9439 births including 91 twins giving an incidence of 9.64 per 1000 births. In the present study, 88 cases (96.7\%) were booked whereas 3 cases (3.3\%) were unbooked.

\begin{tabular}{|c|c|c|}
\hline Age in Years & Number & \% \\
\hline$<20$ & 8 & $8.79 \%$ \\
\hline $20-29$ & 69 & $75.82 \%$ \\
\hline $30-35$ & 10 & $10.98 \%$ \\
\hline$>35$ & 4 & $4.39 \%$ \\
\hline \multicolumn{2}{|c|}{ Table I: Age Incidence in Twin Pregnancy (N=91) }
\end{tabular}

Maximum incidence of twin pregnancies were in the age group of $20-29$ years $(75.82 \%) .3 .29 \%$ were teenage pregnancies and $4.39 \%$ were elderly.

\begin{tabular}{|c|c|c|}
\hline Parity & Number & \% \\
\hline Primi & 36 & $39.56 \%$ \\
\hline Multi & 52 & $57.14 \%$ \\
\hline Grand Multi & 3 & $3.29 \%$ \\
\hline
\end{tabular}

Table II: Parity Incidence in Twin Pregnancy (N=91)

The parity distribution of patients shows $57.14 \%$ were multiparous and $39.56 \%$ were primiparous.

\begin{tabular}{|c|c|c|c|}
\hline & Gestation in Wks. & Number & $\%$ \\
\hline Term & $>37$ & 32 & $35.16 \%$ \\
\hline Borderline Term & $34-36$ & 39 & $42.85 \%$ \\
\hline Preterm & $30-34$ & 20 & $21.97 \%$ \\
\hline \multicolumn{2}{|r|}{$\begin{array}{r}\text { Table III: Incidence of Twin Pregnancy } \\
\text { in Relation to Gestational Age (N=91) }\end{array}$}
\end{tabular}

Nearly $64.82 \%$ had preterm delivery and $35.16 \%$ had term delivery. The main cause for increased frequency of preterm labour in twins was found to be due to over distension of the uterus. This hypothesis originated from observations, which demonstrated a direct correlation between uterine stretching and initiation of parturition. Another hypothesis is that intrauterine infection is an important cause of preterm labour in twins, which was due to the early opening of the cervix as a result of excessive growth of the uterus leading to exposure of foetal membranes to the bacterial flora of the vagina.

In pregnancies with gestational age $<34$ weeks around $15(16.48 \%)$ received corticosteroid therapy before delivery. Forty nine preterm cases $(53.84 \%)$ received prophylactic antibiotics before delivery.

\begin{tabular}{|c|c|c|}
\hline Pregnancy Complication & Number & $\mathbf{\%}$ \\
\hline Hyperemesis Gravidarum & 6 & $6.59 \%$ \\
\hline Preterm Labour & 23 & $25.27 \%$ \\
\hline PROM & 12 & $13.18 \%$ \\
\hline Anaemia & 34 & $37.36 \%$ \\
\hline Preeclampsia & 16 & $17.58 \%$ \\
\hline Eclampsia & 1 & $1.09 \%$ \\
\hline Polyhydramnios & 2 & $2.19 \%$ \\
\hline Oligohydramnios & 6 & $6.59 \%$ \\
\hline Antepartum Haemorrhage & 4 & $4.39 \%$ \\
\hline Postpartum Haemorrhage & 9 & $9.89 \%$ \\
\hline Gestational Diabetes Mellitus & 1 & $1.09 \%$ \\
\hline Discordant Growth & 4 & $4.39 \%$ \\
\hline No High Risk & 12 & $13.18 \%$ \\
\hline Table IV: Maternal Complications in Twin Pregnancy \\
\hline \multicolumn{2}{|c|}{}
\end{tabular}

The three leading pregnancy complications were anaemia $(37.36 \%)$, preterm labour $(25.27 \%)$, and preeclampsia (17.58\%). In this study, birth weight discrepancy of $20 \%$ or $>20 \%$ between twins was considered as significant discordant growth. Number of such pairs was $4(4.39 \%)$.

\begin{tabular}{|c|c|c|}
\hline Presentation & Cases & \% \\
\hline Cephalic-Cephalic & 53 & $58.24 \%$ \\
\hline Cephalic-Breech & 14 & $15.38 \%$ \\
\hline Breech-Cephalic & 10 & $10.98 \%$ \\
\hline Breech-Transverse & 5 & $5.49 \%$ \\
\hline Breech-Breech & 4 & $4.39 \%$ \\
\hline Cephalic-Transverse & 5 & $5.49 \%$ \\
\hline \multicolumn{2}{|c|}{ Table V: Foetal Presentation at the } \\
Time of Delivery (N=91) \\
\hline
\end{tabular}


This table demonstrates the foetal presentation at delivery. Cephalic-cephalic presentation was the commonest and was found in $58.24 \%$ of the cases while cephalic-noncephalic was found in $20.87 \%$ and non-vertex presentations was found in $20.86 \%$.

\begin{tabular}{|c|c|c|c|c|}
\hline & 1 $^{\text {ST Twin }}$ & $\%$ & 2ND Twin & $\%$ \\
\hline $\begin{array}{l}\text { Vertex Vaginal } \\
\text { Delivery }\end{array}$ & 28 & $30.76 \%$ & 24 & $26.37 \%$ \\
\hline $\begin{array}{l}\text { Assisted Breech } \\
\text { Delivery }\end{array}$ & - & - & 2 & $2.19 \%$ \\
\hline Outlet Forceps & - & - & 1 & $1.09 \%$ \\
\hline LSCS & 63 & $69.23 \%$ & 64 & $70.32 \%$ \\
\hline
\end{tabular}

In this study, $30.76 \%$ of first twin had normal vaginal delivery while $26.37 \%$ of second twin had normal vaginal delivery. $69.23 \%$ of first twin was delivered by caesarean section while $70.32 \%$ of second twin was delivered by caesarean section. In one patient alone, first twin was delivered vaginally while second twin was delivered by caesarean section because of transverse lie of second twin with failed internal podalic version.

\begin{tabular}{|c|c|c|}
\hline & Number & \% \\
\hline$<1 \mathrm{Min}$ & 32 & $35.16 \%$ \\
\hline 1-5 Min & 35 & $38.46 \%$ \\
\hline $5-10 \mathrm{Min}$ & 13 & $14.28 \%$ \\
\hline$>10 \mathrm{Min}$ & 7 & $7.69 \%$ \\
\hline$>20 \mathrm{Min}$ & 4 & $4.39 \%$ \\
\hline \multicolumn{2}{|c|}{ Table VII: Twin-Twin Delivery Interval (N=91) } \\
\hline
\end{tabular}

Second twin was delivered within five minutes in $73.62 \%$ of deliveries.

\begin{tabular}{|c|c|c|}
\hline Weight & Number & \% \\
\hline$<1.5 \mathrm{~kg}$ & 26 & $14.28 \%$ \\
\hline $1.5-2 \mathrm{~kg}$ & 48 & $26.37 \%$ \\
\hline $2-2.4 \mathrm{~kg}$ & 70 & $38.46 \%$ \\
\hline$>2.5 \mathrm{~kg}$ & 38 & $20.87 \%$ \\
\hline \multicolumn{2}{|c|}{ Table VIII: Baby Birth Weight in Twins (N=182) }
\end{tabular}

$20.87 \%$ of babies had birth weight of $>2.5 \mathrm{~kg}$ while $79.13 \%$ of babies had low birth weight or very low birth weight.

\begin{tabular}{|c|c|c|}
\hline Type of Placenta & Number & \% \\
\hline Diamniotic Dichorionic & 55 & $60.43 \%$ \\
\hline Diamniotic Monochorionic & 32 & $35.16 \%$ \\
\hline Monoamniotic Monochorionic & 4 & $4.39 \%$ \\
\hline \multicolumn{2}{|c|}{ Table IX: Placentation in Twin Pregnancy (N=91) } \\
\hline
\end{tabular}

Most common type of placentation observed was diamniotic-dichorionic, which constitutes about $60.43 \%$ of the cases while the least common type was monoamnioticmonochorionic twins, which constituted about $4.39 \%$.

\begin{tabular}{|c|c|c|c|c|}
\hline Morbidity & $\begin{array}{c}\mathbf{1}^{\text {st }} \\
\text { Twin }\end{array}$ & $\mathbf{\%}$ & $\begin{array}{c}\mathbf{2}^{\text {nd }} \\
\text { Twin }\end{array}$ & \% \\
\hline VLBW & 12 & $13.18 \%$ & 14 & $15.38 \%$ \\
\hline LBW & 40 & $43.95 \%$ & 43 & $47.25 \%$ \\
\hline RDS & 8 & $8.79 \%$ & 6 & $6.59 \%$ \\
\hline
\end{tabular}

\begin{tabular}{|c|c|c|c|c|}
\hline Birth Asphyxia & - & & 4 & $4.39 \%$ \\
\hline Sepsis & 2 & $2.19 \%$ & 3 & $3.29 \%$ \\
\hline $\begin{array}{c}\text { Congenital } \\
\text { Anomaly }\end{array}$ & 1 & $1.09 \%$ & 3 & $3.29 \%$ \\
\hline $\begin{array}{c}\text { Meconium } \\
\text { Aspiration } \\
\text { Syndrome }\end{array}$ & 3 & $3.29 \%$ & 1 & $1.09 \%$ \\
\hline \multicolumn{5}{|c|}{ Table X: Neonatal Morbidity in Twins } \\
\hline
\end{tabular}

No. of NICU Admissions=113(62.08\%).

The incidence of perinatal morbidity that required admissions in neonatal ICU was $62.08 \%$. Among them, the leading cause of perinatal morbidity was found to be due to low birth weight $(43.95 \%$ in first twin and $47.25 \%$ in second twin). Apart from the data shown in the table four babies had specific problems.

1. One baby had meningomyelocele. The other baby of the twin pair was normal.

2. In another pair, one of the twins was born with imperforate anus while the other twin was normal.

3. In a third pair of twins, one baby had meningomyelocele while its twin had tracheoesophageal fistula with hydrocephalic changes.

\begin{tabular}{|c|c|c|}
\hline Deaths & Number & \% \\
\hline First Twin & 8 & $4.39 \%$ \\
\hline Second Twin & 11 & $6.04 \%$ \\
\hline Total & $\mathbf{1 9}$ & $\mathbf{1 0 . 4 3 \%}$ \\
\hline \multicolumn{2}{|c|}{ Table XI: Neonatal Mortality in Twins } \\
\hline
\end{tabular}

The neonatal mortality in our study was $10.43 \%$ of which the mortality of second twin was higher (6.04\%) when compared to the first twin.

\begin{tabular}{|c|c|c|}
\hline Causes & Number & \% \\
\hline Preterm/RDS & 10 & $52.63 \%$ \\
\hline Sepsis & 4 & $21.05 \%$ \\
\hline Birth Asphyxia & 2 & $10.52 \%$ \\
\hline Congenital Anomaly & 3 & $15.78 \%$ \\
\hline \multicolumn{2}{|c|}{ Table XII: Causes of Neonatal Mortality (N=19) }
\end{tabular}

In our study, it was observed that perinatal mortality was mainly in preterm babies $89.48 \%$ with only two deaths $(10.52 \%)$ in term babies due to birth asphyxia. The three most common causes of neonatal mortality was prematurity/respiratory distress syndrome, which constitutes about $52.63 \%$ while sepsis constitutes about $21.05 \%$ and congenital anomaly constitutes about $15.78 \%$.

\section{DISCUSSION}

In the present study, prevalence of twin pregnancy is 9.64 per 1000 births in our hospital, which corresponds to the quoted Asian incidence.(2) 75\% belonged to age group of 20-30 years (Table I) since most of the pregnancies occur during this period. This study also shows that $57 \%$ of them were multigravid, which is similar to study done by Dr. Deepthi H. R. et al (50\%),(7) Chowdhury $S$ et al (64.2\%).(8) Incidence of preterm delivery is $65 \%$. It is found to be high when compared to study done by Sultana et al,(9) but correlates well with Narongwat Suriya et al (62.9\%)(10) and Deepthi et al (60\%).(7) 
Majority of the twins is born around 34-36 weeks. Incidence of low birth weight $(<2.5 \mathrm{~kg})$ was $79.13 \%$ in this study, which was similar to the study of Bangal et al (82\%).(11)

Pregnancy complications were shown in (Table-IV). Most common were preterm labour (25.27\%), anaemia (37.36\%), preeclampsia (17.58\%), and PROM (13.18\%), which is mostly similar to study by Deepthi et al. ${ }^{7}$ In this study, almost two thirds of women $(70 \%)$ were delivered by caesarean section out of which $20 \%$ were repeat caesarean deliveries. Caesarean section rate is similar to Sultana et al study (68\%). ${ }^{9}$ No maternal mortality is seen in our study.

In our study, perinatal morbidity requiring neonatal admissions were $62.08 \%$ mainly for prematurity, low birth weight, and respiratory distress. Perinatal mortality found in our study was $10.43 \%$. Several studies also reported similar perinatal mortality rate (Sultana et al 11\%, Bangal et al 10\%).9,11 Slightly increased perinatal mortality was observed in second twin (Table XI). We found only 3 neonatal deaths after 34 weeks. All other deaths are seen in less than 34 weeks gestational age group. Hence, prematurity and low birth weight appears to be the major risk factor that increases the rate of neonatal death in twin pregnancy.

\section{CONCLUSION}

Preterm delivery and prematurity are the important problems identified in twin pregnancy and were the leading cause of perinatal mortality. So, prevention of preterm labour along with good neonatal intensive care unit for preterm babies will definitely bring down the mortality in twin pregnancies.

\section{REFERENCES}

1. American Society of Reproductive Medicine. Multiple pregnancy and birth considering infertility treatment: twin, triplets, and higher order multiples 2004.
2. Chittacharoen A, Singhakun D, Ayudhya NI. A pregnancy outcome of twin pregnancy in Ramathibodi Hospital. J Med Assoc Thai 2006;89(Suppl 4):S76-80.

3. Cruikshank DP. Intrapartum management of twin gestations. Obstet Gynaecol 2007;109(5):1167-76.

4. Obiechina NJ, Okolie VE, Eleje GU, et al. Twin versus singleton pregnancies: the incidence, pregnancy complications, and obstetric outcomes in a Nigerian Tertiary Hospital. Int J Womens Health 2011;3:227-30.

5. Smits J, Monden C. Twinning across the developing world. PLoS One 2011;6(9):e25239.

6. Sumathipala A, Siribaddana S, De Silva N, et al. Sri Lankan twin registry. Twin Res 2002;5(5):424-6.

7. Deepthi HR, Pradeep MR, Lalitha S. Retrospective study of maternal and perinatal outcome in twin pregnancy in a teaching hospital. IOSR Journal of Dental and Medical Sciences 2015;14(1):29-32.

8. Chowdhury S, Hussain MA. Maternal complications in twin pregnancies. Mymensingh Med J 2011;20(1):83-7.

9. Sultana M, Khatun S, Ara R, et al. Maternal and perinatal outcome of twin pregnancy in a tertiary hospital. Ibrahim Card Med J 2011;1(2):35-9.

10. Suriya N, Yuthavisuthi P. Pregnancy and perinatal outcomes of twin pregnancies in Prapokklao Hospital. Thai Journal of Obstetrics and Gynaecology 2010;18(4):165-71.

11. Bangal VB, Patel SM, Khairnar DN. Study of maternal and foetal outcome in twin gestation at tertiary care teaching hospital. International Journal of Biomedical and Advance Research 2012;3(10):758-61. 